\title{
THE IMMEDIATE EFFECT ON THE COMPLEMENT. FIXATION TEST FOR LUES OF TREATMENT WITH SALVARSAN (ARSENOBENZOL)
}

\author{
AN ANALYSIS OF 225 CASES* \\ CHARLES F. CRAIG, M.D. + \\ WASHINGTON, D. c.
}

In reviewing the literature on the results of the treatment of lues with salvarsan, one is impressed with the unsatisfactory nature of the data regarding the effect of treatment with this drug on the complement fixation test. It is now generally acknowledged that this test is the only exact index we possess of the efficacy of any method of treatment of lues; indeed, Ehrlich" does not hesitate to say that "the observation of the Wassermann reaction represents the most valuable method we have' of seeing clearly whether the syphilis is genuinely eured," and this opinion is supported by every authority having to do with the treatment of the disease.

In view of the importance of the complement fixation test as a control of the efficacy of treatment with salvarsan, I have thought that an analysis of 225 cases, showing the immediate effect of such treatment on the test, would be of interest and value. I have used the term "immediate effect" because it is yet too early to speak of the ultimate effect of this method of treatment on the complement fixation test. It is believed that the data obtained from the cases reported on are especially valuable, because in the vast majority numerous tests have been made at frequent intervals, thus giving one a more just conception of the exact effect of treatment with this drug on the complement fixation test. It will be observed that an early disappearance of a positive reaction is more frequently noted in this series of cases than is reported by most observers, largely owing to the fact that the tests were made at frequent intervals, a practice possible only in the military service or where luetic patients can be kept under constant observation for long periods of time. In the military service, also, it is possible to secure more accurate data regarding the date of infection and the nature and extent of previous treatment,

*From the Bacteriologic Laboratory of the Army Medical School, Washington, D. C.

${ }^{*}$ Published with the authority of the Surgeon General, U. S. Army.

†Captain, Medical Corps, U. S. Army.

1. Ehrlich, P.: Chemotherapy, Ed. 1, New York, 1911, p. 116. 
facts of great importance in any consideration of the effect of treatment with salvarsan on the complement fixation test.

Before considering the results obtained in this laboratory, it is necessary briefly to discuss the exact clinical significance of the positive and negative reaction after treatment with salvarsan. I believe that it may be stated without hesitation that a positive Wassermann reaction means the presence of living spirochetes and is always an indication for further treatment, provided a sufficient time has elapsed for the reaction to become negative, as shown by experience. On the other hand a negative reaction does not necessarily mean that all the spirochetes are destroyed, for relapses may occur after the reaction has been negative for weeks or even months. A negative reaction may, therefore, mean either a complete cure or only the destruction of a sufficient number of the spirochetes to prevent the appearance of the reaction. The latter statement is supported by the occurrence of cases in which the patients are suffering from a clinical relapse, but in which the complement fixation test remains negative for some time. In one such case the spirochetes were demonstrated in the lesions at the time of the relapse, although the reaction was still negative, thus proving that the mere presence of the parasites is not always accompanied by a positive Wassermann test. Wellmarked clinical cases of lues are also observed, in which the Wassermann test is negative, although the lesions contain the spirochetes and no treatment has been administered. It would, therefore, appear as though the appearance of a positive reaction depends on quantitative phenomena or on reactions of the tissues to the spirochetes which may not occur under certain conditions.

As I have stated the literature regarding the effect of treatment with salvarsan on the complement fixation test is limited in amount, and much of it is unsatisfactory in character. While many authorities have reported very fully the clinical results in thousands of patients so treated the serologic data are generally incomplete, many of the most valuable clinical reports containing either no mention of the results of the complement fixation test or recording them inaccurately or in such a way that no definite conclusions can be drawn from them. A few writers, however, have reported in detail the results of the Wassermann test in their cases but it is difficult to judge of their value, as a whole, on account of the lack of data regarding many important factors having to do with the time of disappearance of the reaction. A brief abstract is given of the most important contributions to this subject.

Nichols and Fordyce ${ }^{2}$ report the results of the Wassermann test in eleven patients treated with salvarsan. In eight the reaction became negative, one in nineteen days; two in twenty-one days; one in twenty-three days; one in twentyfive days; one in thirty-nine days; one in three months; and one in three months

2. Nichols, H. J., and Fordyce, J. A.: Jour. Am. Med. Assn., 1910, 1v, 1171. 
and eleven days. Of these cases, two are still negative at the end of ten months, a period of time sufficient, I believe, to prove that they are cured. In both of these cases, the dose of arsenobenzol was only $0.3 \mathrm{gm}$. Relapses occurred in two cases and the remainder have disappeared.

Geronne and Huggenberg ${ }^{3}$ report ten cases in which a plus reaction became negative in from four to ten weeks. In four cases it remained positive, one after fifty-six days; and one after seventy days. In twenty-five cases observed for less than four weeks only six became negative.

Michaelis ${ }^{4}$ treated 110 patients and observed only three relapses. He states that the serum reaction may become negative within a period from two to ten weeks after the injection. He observed in some instances a strengthening of the reaction after treatment, although the clinical symptoms were disappearing.

Fordyce $e^{5}$ states that the results of the Wassermann test after " 606 " have varied within wide limits but in general a change occurred in from four to five weeks. The earliest change from a positive to a negative reaction observed by him was in six days after the injection, but in another case, after two injections, the reaction did not become negative until fifty-two days. Another case, after two injections, was still positive after seventy-four days and another after 102 days. He says that "several eases showed alternating negative and positive phases."

Herxheimer ${ }^{8}$ records the results of 789 treated cases of which thirty-three relapsed in a period of five months. Many of his patients disappeared before a negative reaction was obtained. He observed a negative reaction in two primary cases after seven and twenty days, while four cases which were negative before the treatment became positive afterwards. Of thirty secondary cases that became negative after treatment, five became negative in from one to two weeks, the others at later periods. In seven latent cases, three became negative in from eight to fourteen days.

Weintraud ${ }^{7}$ reports that in only thirty-seven out of seventy-seven patients, did the Wassermann reaction become permanently negative, and that in three cases it remained positive after three injections of arsenobenzol.

Table 1.--Results of Complement Fixation Test after Treatament with Salvarsan (FAVENTo)

- Time of Disappearance of Reaction in Weeks-

\begin{tabular}{|c|c|c|c|c|c|c|c|c|c|c|}
\hline $\begin{array}{l}\text { Stage of } \\
\text { Disease }\end{array}$ &  & 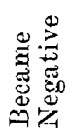 & $\frac{y}{3}$ & 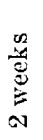 & 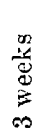 & 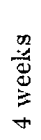 & 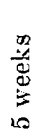 & 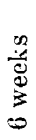 & $\begin{array}{l}\text { की } \\
\text { यै } \\
0 \\
3 \\
\vdots\end{array}$ & 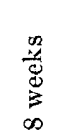 \\
\hline Primary & 0 & 15 & 1 & 4 & 2 & 3 & 4 & 0 & 0 & 1 \\
\hline Secondary & 12 & 16 & 1 & 4 & 2 & 3 & 3 & 3 & 0 & \\
\hline Tertiary .... & 4 & 1 & 0 & 0 & 1 & 0 & 0 & 0 & 0 & 0 \\
\hline Totals .... & 16 & 32 & 2 & 8 & $\tilde{5}$ & 6 & 7 & 3 & 0 & \\
\hline
\end{tabular}

Favento ${ }^{s}$ records very carefully the serologic data in forty-eight cases of lues in which salvarsan was used, Table 1 giving his results.

It will be observed that the majority of his cases became negative in from two to five weeks after the injection. Some of his positive cases were only observed for three or four weeks and, therefore, may have become negative later.

3. Gerrone and Huggenberg: Berl. klin. Wehnschr., 1910, xlvii, 28.

4. Michaelis, L.: Berl. klin. Wchnschr., 1910, xlvii, 1195.

5. Fordyce, J. A.: New York Med. Jour., 1911, xcii, 897.

6. Herxheimer, G.: Deutsch. med. Wchnschr., 1910, xxxvii, 1517.

7. Weintraud, C.: Med. Klin., 1910, xliii, 183.

8. Favento, A.: München. med. Wehnschr., 1910, lvii, 2080. 
Noguchi ${ }^{9}$ has recently published a very valuable serological analysis of 102 cases, in which the patients were treated with salvarsan. He states that more than half of the number were under observation for over three months, while the remainder had been injected for four weeks. He conducted a quantitative determination of the serum reaction in each case, the blood being examined before the injection and at intervals of one day, three days, one week, two weeks, three weeks, four weeks, six weeks, eight weeks, etc., after the injection. He found that thirty cases became negative, twenty-four reduced to less than 1 antibody unit, while the remaining forty-eight cases still contain more than $l$ antibody unit, giving strong positive reactions. However, a titration of the serum of these cases showed that they were decidedly reduced in antibody content, although they gave strong reactions. In 40 per cent. of the primary cases; in 37 per cent. of secondary; in 35 per cent. of tertiary; in 33 per cent. of latent; in 14 per cent. of hereditary; and in 50 per cent. of incipient tabes, the reaction became negative. The average of the negative reactions equaled 33.7 per cent. of the total 102 cases. Ten relapses were observed; six of the patients were reinjected with good results and one had a second relapse. Of the negative cases reported by Noguchi, thirty-four in number, three became negative in two weeks; ten in three weeks; eleven in four weeks; five in five weeks; four in six weeks; and one in seven weeks. His results in this respect are similar to those obtained in this laboratory.

It will be noted that there is the greatest variation in the results obtained by different observers, and the number of cases which have been reported serologically is very" small when compared with the vast number in which salvarsan treatment has been used. The difference in results may be explained by the class of patients treated by different observers, the amount and kind of previous mercurial treatment, and, perhaps, by the technic employed in making the tests.

THE DISAPPEARANCE OF THE REACTION IN RABBITS INFECTED WITH LUES AND YAWS

Through the kindness of Captain Nichols of the Army Medical Corps, I have recently had the opportunity of testing rabbits experimentally infected with lues and yaws, and of observing the complement fixation curve as shown by the titration of the serum of these animals, as regards its complement fixation qualities. Table 2 illustrates the results obtained in an animal infected with lues and Table 3 in one infected with yaws; these well show the gradual increase in the anti-body strength of the serum and the disappearance of the positive reaction after the administration of salvarsan.

An examination by Captain Nichols of Rabbit 39, infected with lues, demonstrated the presence of spirochetes on January 19, but the Wassermann test was not positive, even with 0.2 c.c. of serum, until January 23 . From this time it gradually increased in strength until February 6, at which time 0.05 c.c. of the serum gave a double-plus reaction. At this time Captain Nichols administered intravenously $0.02 \mathrm{gm}$. of salvarsan per kilo and the reaction became negative on January 13, one week

9. Noguchi, H.: Serum Diagnosis of Syphilis, Ed. 2, Philadelphia, 1911. 
after treatment. It is interesting to observe that the reaction diminished in strength on the 8 th, and increased in strength on February 10, after treatment.

In Rabbit 44, infected with yaws, the spirochetes were demonstrated by Captain Nichols on January 21, but the Wassermann test did not become positive until January 30. On February 6, when 0.05 c.c. of the serum gave a double-plus reaction, $0.02 \mathrm{gm}$. of salvarsan per kilo was administered intravenously by Captain Nichols, and on February 13 the reaction became negative, one week after treatment. Here again it is interesting to observe a diminution in the strength of the reaction two days after treatment, an increase four days after treatment, and a final disappearance three days later. Similar phenomena have been noticed in human subjects, a negative reaction becoming positive after treatment or weak reactions becoming strong for a short period after the administration of salvarsan. Ehrlich believes that such changes in the reaction are due to the reaction of the tissues to poisons liberated by the destruction of the spirochetes.

Table 2.-Results of Complement Fixation Test Before and After TreatMent witu Salvarsan in Rabitt 39, Infected witil Lues*

\begin{tabular}{|c|c|c|c|c|c|c|c|c|c|}
\hline \multirow{2}{*}{\multicolumn{2}{|c|}{$\begin{array}{l}\text { Amount } \\
\text { of Serum }\end{array}$}} & \multicolumn{8}{|c|}{ Date of Tests } \\
\hline & & $1 / 23$ & $1 / 27$ & $1 / 30$ & $2 / 6$ & $2 / 8$ & $2 / 10$ & $2 / 13$ & $2 / 18$ \\
\hline 0.05 & c.c. & 一 & + & + & $+t$ & - & + & 0 & 一 \\
\hline 0.10 & c.c. & - & ++ & ++ & ++ & \pm & $t+$ & - & - \\
\hline 0.15 & c.c. & 0 & $+t$ & ++ & ++ & \pm & ++ & 0 & - \\
\hline 0.20 & c.c. & ++ & 0 & ++ & ++ & \pm & ++ & - & \\
\hline
\end{tabular}

* Spirochetes found in testicular lesion Jan. 19, 1911; $0.02 \mathrm{gm}$. salvarsan per kilo administered intravenously Feb. 6, 1911.

Table 3.-Results of Complement Fixation Tests Before and After TreatMent with Salvarsan in RabBit 44, Infected with Yaws*

Amount

of Serum

of Ser

0.05 c.c. $\ldots \ldots \ldots \ldots$

0.10 c.c.........

0.15 c.c........

0.20 c.c.........

* Spirochetes found in lesion Jan. administered intravenously Feb. 6, 1911.
Date of 'Tests

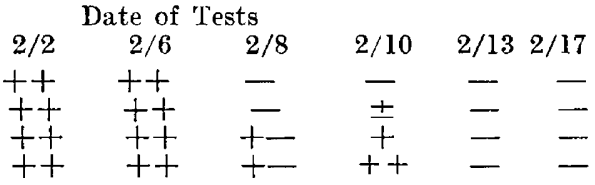

0.02 gm. salvarsan per lilo

The results in this laboratory of the complement fixation tests in experimentally infected animals before and after treatment with salvarsan have been perfectly consistent throughout and prove indubitably the specific action of this drug on the spirochetes of syphilis and yaws.

\section{TECHNIC AND GENERAL RESULTS}

The technic used in making the tests in this laboratory is largely that recommended by Noguchi. A human hemolytic system has been used, the amboceptor being obtained from rabbits immunized against human 
red corpuscles. As antigen we have used an extract of luetic fetal liver in absolute alcohol and the serum tested has always been inactivated. As we receive our specimens from army posts, many of them located at considerable distances from the laboratory, we use only inactive serum and for this reason have preferred an alcoholic extract as antigen. Guinea-pig serum has been used for complement. One cubic centimeter of a 1 per cent. suspension of red corpuscles is used for the antigen and control tubes. The technic of making the test will not be considered, as it is familiar to all who are interested in the Wassermann reaction.

Our tests have been controlled by repeated tests made at the same time on known clinical cases and the results have always been consistent.

At the present writing complement fixation tests are being made in this laboratory on over 700 soldiers who have been treated with salvarsan, but $I$ have only considered the results in 225 cases, for the reason that the remainder have not been observed for a sufficient time for the data to be of definite value. Of the cases reported on all have been observed for at least eight weeks since the administration of the drug and most of them for a longer period.

Of the 225 cases reported 164 , or 72.8 per cent., became negative and sixty-one, or $2 \% .1$ per cent., have remained positive. Of the 164 cases which became negative, twenty-four, or 14.6 per cent., have relapsed; forty-three have remained negative for two months; forty-one for two and one-half months; twenty for three months; seven for four and one-half months; eleven for five and one-half months; seven for six months, and six for seven months. It is probable that some of these cases will relapse later, but it is not believed that relapses will occur in a very large proportion of them.

A number of important factors must be considered in order to understand the exact value of these data. The number of cases which remain positive, or become negative after the administration of salvarsan is of little practical significance unless we are informed as to the stage of the disease in which the drug is administered; the intensity of the positive reaction; the method of administration, and the amount and kind of previous mercurial treatment. In view of the importance of these factors, I have endeavored to give a complete analysis of the cases in these respects, and $I$ believe that the real effect of treatment with salvarsan on the complement fixation test can be accurately ascertained only when such an analysis is made. In the literature dealing with this subject but little attention seems to have been paid to the factors which I have mentioned, and therefore much of it is comparatively valueless. 
IHE STAGE OF THE DISEASE IN RELATION TO THE DISAPPEARANCE OF THE REACTION

The results obtained in this laboratory show that the immediate effect of treatment with salvarsan on the complement fixation test is much influenced by the stage of the disease. In Table 4 is given an analysis of the cases reported, showing the number becoming negative and remaining positive in the various stages of lues. The data are based on the results of one injection of salvarsan in all but a few cases, the dose employed varying from 0.5 to $0.8 \mathrm{gm}$.

Table 4.-The Result of Treatment with Salvarsan on Complement FixaTION IN THE Various Stages of Lues

\begin{tabular}{|c|c|c|c|c|c|c|c|}
\hline $\begin{array}{c}\text { Stage of } \\
\text { Disease }\end{array}$ & $\begin{array}{r}\text { No. of } \\
\text { Cases }\end{array}$ & $\begin{array}{c}\text { Became } \\
\text { Negative }\end{array}$ & $\begin{array}{c}\text { Per } \\
\text { Cent. }\end{array}$ & $\begin{array}{c}\text { Remained } \\
\text { Positive }\end{array}$ & $\begin{array}{l}\text { Per } \\
\text { Cent. }\end{array}$ & $\begin{array}{c}\text { Relapsed } \\
\ldots \ldots \ldots\end{array}$ & $\begin{array}{l}\text { Per } \\
\text { Cent. }\end{array}$ \\
\hline Primary & 31 & 25 & 80.6 & 6 & 19.4 & 3 & 12 \\
\hline Secondary & 135 & 100 & 74 & 35 & 25.9 & 15 & 15 \\
\hline Tertiary & 22 & 12 & 54.9 & 10 & 45 & 2 & 16.6 \\
\hline Latent & 37 & 27 & 72.9 & 10 & 27 & 4 & 14.8 \\
\hline Totals & 225 & 164 & 72.8 & 61 & 27 & 24 & 14.6 \\
\hline
\end{tabular}

It will be observed from a consideration of the table that of thirtyone primary cases 80.6 per cent. became negative, while 12 per cent. relapsed. In the secondary cases 135 in number, 74 per cent., became negative, of which 15 per cent. relapsed. In the tertiary cases twentytwo in number, 54.9 per cent., became negative, of which 16.6 per cent. relapsed, and in the latent cases thirty-seven in number, 72.9 per cent. became negative and 14.8 per cent. relapsed. It is thus evident that the best results were obtained, as regards the disappearance of the reaction, in the treatment of patients in the primary stage and the most unfavorable in the treatment of patients in the tertiary stage. In latent cases the results are apparently somewhat better than in the secondary cases, and it is interesting to note the gradual decrease in the efficacy of the treatment the older the active stage of the disease. The results obtained are as might be expected and indicate the value of early treatment of luetic infections.

The time of disappearance of the reaction in the cases which became negative has also varied with the stage of the disease. In Table 5 is given the date of disappearance of the reaction in weekly periods correlated with the stage of the infection.

It will be noted that, considering the total number of cases, the greatest number became negative during the second, third and fourth weeks, that a considerable number became negative one week after injection, and that, in our experience, none of the cases became negative after eight weeks. I believe that unless the reaction becomes negative within this time it will not become so later, in the vast majority of cases, and 
that a positive reaction after this period should always be considered an indication for further treatment.

In regard to the time of disappearance of the reaction in relation to the stage of the disease, it will be noted that the best results were obtained in the tertiary stage, no less than nine of the twelve tertiary cases becoming negative within two weeks, and that four weeks was the longest time after treatment in which the reaction became negative at this stage of the disease. In the secondary cases the reaction disappeared most frequently during the second, third and fourth weeks, while the longest period was eight weeks. In the primary cases thirteen of the twenty-five cases became negative within two weeks, while five weeks was the longest period after treatment that the reaction became negative. In latent cases the majority became negative during the second, third, fourth and fifth weeks, and no case became negative after six weeks.

Table 5.-The Relation of the Stage of Lues to tile Time of Disappearance of Complement Frxation, After Treatment with Salvarsan

- Time of Disappearance of Reaction —

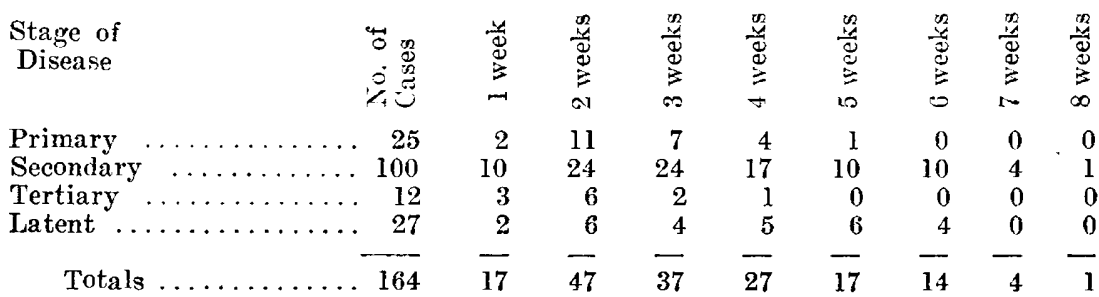

The favorable results obtained in the tertiary cases, as regards the disappearance of the reaction, coincide with the remarkable influence of salvarsan on the lesions of this stage of the disease, as described by many clinicians, and they would appear to indicate that unjess the reaction becomes negative within a month the majority of the patients require further treatment. In considering our results in this stage of the disease, it should be remembered that almost all of the patients had received more or less vigorous mercurial treatment, which undoubtedly had weakened the infection and thus led to an early disappearance of the reaction after the administration of salvarsan. In fact, in the majority of our cases of secondary, tertiary and latent lues mercurial treatment had been administered and the effect of this on the disappearance of the reaction will be considered later.

\section{THE RELATION OF THE INTENSITY OF COMPLEMENT FIXATION TO THE DISAPPEARANCE OF THE REACTION}

From the study of the intensity of the reaction in the cases here reported on, it is apparent that the stronger the reaction the smaller the number of cases which become negative. In the tables given in this 
paper a double-plus reaction indicates complete inhibition of hemolysis, a plus reaction at least 50 per cent. of inhibition, and a plus-minus reaction less than 50 per cent. of inhibition. Classified in this way the relation of the intensity of the reaction to the time of disappearance is illustrated in Table 6 .

Table 6.-The Relation of tile Intensity of Complement Fixation to the Results of Treatment with Salvarsan

$\begin{array}{cccccccc}\text { Character of } & \text { No. of } & \text { Became } & \text { Per } & \text { Remained } & \text { Per } & \text { Relapsed } & \text { Per } \\ \text { Reaction } & \text { Cases } & \text { Negative } & \text { Cent. } & \text { Positive } & \text { Cent. } & \ldots \ldots \ldots \ldots & \text { Cent. } \\ ++ & 119 & 79 & 66.3 & 40 & 33.6 & 13 & 16.4 \\ + & 71 & 57 & 80.2 & 14 & 19.7 & 7 & 12.2 \\ \pm & 35 & 28 & 80 . & 7 & 20 . & 4 & 14.2 \\ \text { Totals. } & 225 & \mathbb{1 6 4} & \overline{72.8} & \overline{61} & \overline{27.1} & \overline{24} & 14.6\end{array}$

An analysis of this table shows that of 119 cases in which the reaction was double-plus 66.3 per cent. became negative, of which number 16.4 per cent. relapsed. Of seventy-one cases in which the reaction was plus 80.2 per cent. became negative, of which 12.2 per cent. relapsed. Of thirty-five cases in which the reaction was plus-minus 80 per cent. became negative and 14.2 per cent. relapsed. It will be observed that in the double-plus cases a smaller percentage became negative and a larger percentage relapsed than in either the plus or plus-minus cases and it would, therefore, appear that the conclusion is justified that the prognosis, as regards the disappearance of the reaction, is less favorable in cases giving a double-plus reaction. Of course, this is to be expected if the intensity of the complement fixation test is a measure of the severity of a luetic infection, but it is more difficult to explain why the percentage of disappearances is less and of relapses greater in the plusminus cases than in those giving a plus reaction, as shown in the table, although a careful inquiry into the history of our cases indicates why this is so. Nearly half of the cases giving a plus-minus reaction were patients in the late secondary or tertiary stages of the disease in which the infection was still active, although they had been treated vigorously with mercury and the weak reaction in these cases is explained by the fact that mercurial treatment was omitted only a short time before the serum was tested. Had all of our plus-minus cases been in the primary or early secondary stage of the disease I believe that the percentage of disappearance would have been higher than is indicated in the table, while the relapses would have been fewer in number. The relation which the intensity of complement fixation bore to the actual time of disappearance of the reaction in the 164 cases which became negative is shown in Table $\%$. 
This table shows that most of the cases giving a double-plus reaction became negative during the second, third and fourth weeks after treatment, the greatest number during the second week, but that no less than eight became negative during the first week after treatment. The results were similar in the cases giving a plus reaction, although a smaller number, proportionately, became negative in the first week. As would be expected the cases giving a plus-minus reaction showed the largest proportion becoming negative in the first week but some did not become so until the fifth and sixth week. The quickest results were obtained in the plus-minus cases, considered as a whole, while the results in the double-plus and plus cases were practically the same.

Table 7.-The Reiation of the Intensity of Complement Fixation to the Time of Disappearayce of the Reaction After Treatment with Salvarsan

Time of Disappearance of Reaction-

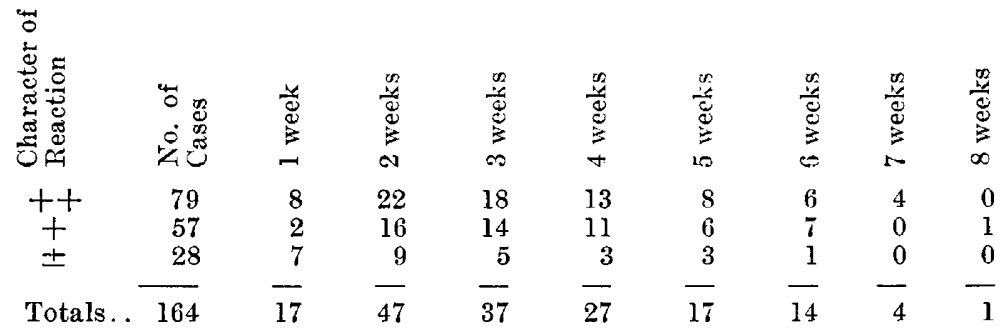

The early disappearance of the reaction in the double-plus cases was largely due to the fact that many of these were primary and secondary cases, some of which had received previous mercurial treatment, and the amount and kind of such treatment must always be considered in interpreting the real meaning of early disappearances of the reaction.

The relation of the stage of the disease and the intensity of the reaction to the time of its disappearance after treatment with salvarsan is shown in Table 8 .

In analyzing this table it is necessary to consider the intensity of the reaction in relation to its disappearance in each stage of the disease. Of the twelve primary cases giving a double-plus reaction 83.3 per cent. became negative, of which 30 per cent. relapsed; of the seventysix secondary cases giving a double-plus reaction 63.1 per cent. became negative, of which 18.9 per cent. relapsed; of the ten tertiary cases with a double-plus reaction 40 per cent. became negative and 50 per cent. relapsed, and of the twenty latent cases giving a double-plus reaction 70 per cent. became negative, of which 14.2 per cent. relapsed.

Considering these cases as a whole it will be observed that the best results, as regards the disappearance of the reaction, were obtained in the primary stage and the poorest in the tertiary stage, while better results were obtained in the secondary stage than in latent infections. When 
relapses are considered, however, the best results were obtained in the latent cases and the poorest in the tertiary cases; the secondary stage gave better results as regards relapses than the primary and this was not due, as might be thought, to either the method of the administration of the drug or to the dosage.

Table 8.-Relation of the Stage of lues and the Intenstiy of the Complement Fixation Reaction to its Disappearance After Treatment with Salvarsan

\begin{tabular}{|c|c|c|c|c|c|c|c|}
\hline $\begin{array}{l}\text { Stage of Disease } \\
\text { and No. of Cases }\end{array}$ & $\begin{array}{c}\text { Character of } \\
\text { Reaction }\end{array}$ & $\begin{array}{l}\text { Became } \\
\text { Negative }\end{array}$ & $\begin{array}{l}\text { Per } \\
\text { Cent. }\end{array}$ & $\begin{array}{c}\text { Remained } \\
\text { Positive }\end{array}$ & $\begin{array}{l}\text { Per } \\
\text { Cent. }\end{array}$ & $\begin{array}{l}\text { Relapsed } \\
\ldots \ldots \ldots\end{array}$ & $\begin{array}{l}\text { Per } \\
\text { Cent. }\end{array}$ \\
\hline Primary & ++ & 10 & 83.3 & 2 & 16.6 & 3 & 30 \\
\hline \multirow[t]{2}{*}{31 cases } & + & 10 & 83.3 & 2 & 16.6 & 0 & 0 \\
\hline & \pm & 5 & 71.4 & 2 & 28.5 & 0 & 0 \\
\hline Secondary & ++ & 48 & 63.1 & 28 & 36.8 & 9 & 18.9 \\
\hline \multirow[t]{2}{*}{135 cases } & + & 39 & 86.6 & 6 & 13.3 & 5 & 12.8 \\
\hline & \pm & 13 & 92.8 & 1 & 7.1 & I & 7.6 \\
\hline Tertiary & $+t$ & 4 & 40. & 6 & 60. & 2 & 50. \\
\hline \multirow[t]{2}{*}{22 cases } & + & 5 & 55.5 & 4 & 44.4 & 0 & 0 \\
\hline & \pm & 3 & 100 & 0 & 0 & 0 & 0 \\
\hline Latent & ++ & 14 & 70 & 6 & 30 & 2 & 14.2 \\
\hline \multirow[t]{2}{*}{37 cases } & + & 4 & 50 & 4 & 50 & 1 & 25 \\
\hline & \pm & 9 & 100 & 0 & 0 & 1 & 11 \\
\hline
\end{tabular}

Considering the cases giving a plus reaction the largest percentage of negative results occurred in the secondary stage, the smallest in the latent stage, while better results were obtained in the primary stage than in the tertiary. As regards relapses, none occurred in the primary or tertiary stages, while in the secondary stage 12.8 per cent. relapsed and in the latent cases 25 per cent.

Of the cases giving a plus-minus reaction the table shows that the best results were obtained, as regards the disappearance of the reaction, in the tertiary and latent cases, while the poorest results were obtained in the primary cases. As regards relapses none occurred in the primary or tertiary cases, but 7.6 per cent, relapsed in the secondary stage and 11 per cent. of the latent cases. In the cases in the tertiary and latent stage giving a plus-minus reaction the patients had received vigorous mercurial treatment before the administration of salvarsan, which undoubtedly explains the disappearance of the reaction in all of the cases. The patients who relapsed in the secondary stage had received no previous treatment, while the one patient who relapsed in the latent stage dereloped symptoms a few days after the reaction became negative.

From the data submitted it is evident that the intensity of the reaction in the various stages of the disease is of considerable prognostic import. Thus better results are obtained, as regards the disappearance of the reaction, in the primary cases giving a double-plus reaction than in the secondary, but the chances of a relapse are almost twice as great in the primary as they are in the secondary. It is also interesting to note that the plus-minus cases give a larger percentage of disappearances in 
the secondary than in the primary stages of the disease, but that the chances of a relapse are greater in the secondary stage. The prognosis, as regards the disappearance of the reaction and the occurrences of relapses, is most unfavorable in the tertiary cases which give a doubleplus reaction.

RELATION OF THE METHOD OF ADMINISTRATION OF SALVARSAN TO THE DISAPPEARANCE OF THE COMPLEMENT FIXATION REACTION

I had hoped to be able to give some data regarding the relation of the dosage of salvarsan to the time of disappearance of complement fixation, but in the cases analyzed the dosage has varied so little that no conclusions can be drawn regarding this phase of our subject.

The method of administration, however, had much to do with the disappearance of the reaction as will be seen on consulting Table 9 . The methods used in the cases reported were as follows: Injection of the neutral suspension of the drug; intramuscular injection of the alkaline solution; intravenous injection, and combined intramuscular and intravenous injections.

Table 9.-Variots Methods of Administration of Salvarsan in Rexation to the Disappearaxce of Complement Fixation in Lces

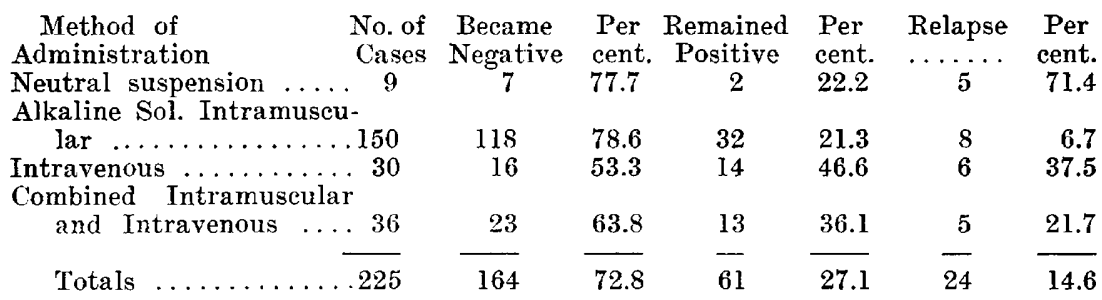

Neutral Suspension.-The neutral suspension of salvarsan was used in nine cases, of which seven became negative and five relapsed. Thus, while the percentage becoming negative was quite large, the percentage of relapses ( 11.4 per cent.) was enormous. It must be admitted that, as a rule, small doses were used, varying from $0.3 \mathrm{gm}$. to $0.5 \mathrm{gm}$., but even taking this into consideration it is evident that the method gives poor results when compared with any of the others mentioned. In justice to the method, however, it should be stated that the two cases which did not relapse, are still negative after a period of nearly ten months.

Intramuscular Injection.- The intramuscular injection of the alkaline solution of salvarsan gave the best results, as regards the disappearance of the complement fixation test, in the cases which are here analyzed. Of the 150 cases so treated 78.6 per cent. became negative, of which only 6.7 per cent. relapsed, and as some of the cases which remained positive have only been observed for a period of four weeks it 
is probable that the percentage of disappearance will become greater within the next two or three weeks, but this may also be true as regards the percentage of relapses. The dose of salvarsan varied from $0.5 \mathrm{gm}$. to $0.6 \mathrm{gm}$.

Intravenous Injection.-The intravenous method was used in thirty of the cases reported, of which 53.3 per cent. became negative and $3 \% .5$ per cent. relapsed.

Seven of the cases were given $0.5 \mathrm{gm}$. of salvarsan, repeated in one week, and of these six became negative, one stayed positive and one relapsed. Four were given $0.6 \mathrm{gm}$. once only, of which one became negative and four remained positive. Nineteen were given $0.5 \mathrm{gm}$. once only, of which nine became negative, ten remained positive and five relapsed. The best results were obtained with two intravenous injections given one week apart.

Combined Intramuscular and Intravenous Injections.-This method was used in thirty-six cases, of which 63.8 per cent. became negative and 21.7 per cent. relapsed, thus giving better results than the intravenous alone, but not as good as the intramuseular method. The dosage employed in the combined method was as follows: $0.2 \mathrm{gm}$. intramuscular $+0.4 \mathrm{gm}$. intravenous; $0.3 \mathrm{gm}$. intramuscular $+0.3 \mathrm{gm}$. intravenous; and $0.6 \mathrm{gm}$. intramuscular $+0.3 \mathrm{gm}$. intravenous. The best results were obtained with the latter dosage, 50 per cent. of the ten cases so treated becoming negative, none of which have relapsed.

A few patients were treated with an intravenous, followed by an intramuscular, injection, but the number is too small to warrant any conclusions regarding the efficacy of this method of treatment.

The period intervening between the administration of the drug by the several methods and the disappearance of the reaction is given in Table 10.

Table 10.- Trme Time of Disappearaxce of the Complement Fixation Reactiox after Treatment with Sajuarsan by Various Methods



This table is of interest as showing the relative rapidity of the disap. pearance of the reaction after the several modes of treatment. It will be observed that the reaction disappeared less rapidly when intra- 
muscular injections were used than when the drug was given intravenously. The great differences in the rapidity of the disappearance of the reaction after treatment with salvarsan are due to numerous factors, some of which are capable of explanation, while others are still unsolved. The situation of the spirochetes, the rate and amount of absorption of the drug and the character and severity of the infection, must all have something to do with the time of disappearance, while the existence of strains of spirochetes, which may be more or less resistant to the drug, a question still undecided, may also explain the slow disappearance of the reaction in certain cases. If, as Ehrlich believes, the fixation reaction may be produced by tissue changes which occur in answer to irritation brought about by the destruction of the spirochetes, it is easy to explain the delayed disappearance of the reaction by a slow elimination of these irritating products. When elimination is rapid, either because the amount of irritating substance is small, or the tissues concerned in elimination are very active, the reaction will disappear quickly, while, if the contrary is true, elimination will be slow and the reaction will persist for a considerable period.

In the intravenous injections twelve of the sixteen negative cases became so within two weeks, while the longest period from the time of the administration of the drug to the disappearance of the reaction was one month. One would naturally expect that the reaction would disappear more rapidly after intravenous injections than after intramuscular and this is borne out by our data. The fact remains, however, that some of these cases did not become negative for three or four weeks, and it is difficult to explain this on any other assumption than that the persistence of the reaction was due to the slow elimination of substances derived from the dead spirochetes or produced by the reaction of the tissues to them. When the drug is given by the intramuscular method it is absorbed slowly, exerting its action for days or perhaps weeks and killing the spirochetes by "the instalment plan" as it were, whereas when it is given intravenously it is absorbed and eliminated rapidly, and any destructive action on the spirochetes must occur in a comparatively short time. In the first case the elimination of the substances which Ehrlich believes have to do with the production of the reaction is gradual, because the spirochetes are being continually destroyed, whereas in the second cases these substances will be eliminated more rapidly because the parasites are all killed within a comparatively short time. The elimination may take some weeks even when the drug is given intravenously, but it will never take so long as when it is given by the intramuscular method, other things being equal. This theory would appear to be contradicted by the results obtained in the cases treated with the neutral suspension, but these cases were very few in number and, therefore, of little value as an argument against the theory. 
RELATION OF PREVIOUS MERCURIAL TREATMENT TO THE DISAPPEARANCE OF COMPLEMENT FIXATION AFTER SALVARSAN

Previous treatment with mercurials has considerable effect on the disappearance of the complement fixation reaction after treatment with salvarsan. This is especially noticeable during certain stages of luetic infection and should always be considered in interpreting the results of various observers as regards this question. As a rule the reaction disappears more quickly in patients who have been subjected to mercurial treatment for some time than in those who have not, and the chances of relapse are less, although, as will be seen, relapses have occurred in patients previously well treated with mercury.

In the 225 cases reported 110 patients had received no treatment previous to the use of salvarsan. Of these eighty-two, or 74.5 per cent., became negative; twenty-eight, or 25.4 per cent., remained positive, and ten or 12.2 per cent. relapsed.

There were seventy-five cases in which a definite history of mercurial treatment was obtained before salvarsan was administered. Of these sixty-three, or 84 per cent., became negative; twelve, or 16 per cent., remained positive, and seven, or 9.3 per cent., relapsed.

From these figures it is evident that better results were obtained in the patients who had previously had mercurial treatment, for not only a larger proportion of the cases became negative, but a smaller proportion relapsed.

The relation of the stage of the disease in patients who had not received previous mercurial treatment to the disappearance of the reaction after salvarsan is shown in Table 11, while in Table 12 is shown the relation of the stage of the disease to the disappearance of the reaction in the patients who had received previous mercurial treatment.

Table 11.-The Relation of the Stage of Lues to the Disappearance of the Complement Fixation Test after Treatment with Salvarsan in Patients who had Received no Paevious Mercurial Treatment

\begin{tabular}{|c|c|c|c|c|c|c|c|}
\hline $\begin{array}{l}\text { Stage of } \\
\text { Disease }\end{array}$ & $\begin{array}{l}\text { No. of } \\
\text { Cases }\end{array}$ & $\begin{array}{l}\text { Became } \\
\text { Negative }\end{array}$ & $\begin{array}{l}\text { Per } \\
\text { cent. }\end{array}$ & $\begin{array}{c}\text { Remained } \\
\text { Positive }\end{array}$ & $\begin{array}{l}\text { Per } \\
\text { cent. }\end{array}$ & $\begin{array}{c}\text { Relapsed } \\
\ldots \ldots \ldots\end{array}$ & $\begin{array}{l}\text { Per } \\
\text { cent. }\end{array}$ \\
\hline rimary & $\ldots 27$ & 22 & 81.4 & 5 & 18.5 & 2 & 9 \\
\hline econdary & . 67 & 48 & 71.6 & 19 & 28.3 & 8 & 16.6 \\
\hline Tertiary & 8 & 5 & 62.5 & 3 & 37.5 & 0 &  \\
\hline Latent ... & 8 & 7 & 87.5 & 1 & 12.5 & 0 & 0 \\
\hline Totals & .110 & 82 & 4.5 & 28 & 25.4 & 10 & \\
\hline
\end{tabular}

In the primary stage, in patients previously untreated, twenty-two, or 81.4 per cent., became negative, while two, or 9 per cent., relapsed, as shown in Table 11. In none of the primary cases were the patients 
given mercurial treatment prior to the administration of salvarsan, so that this column remains empty in Table 12 .

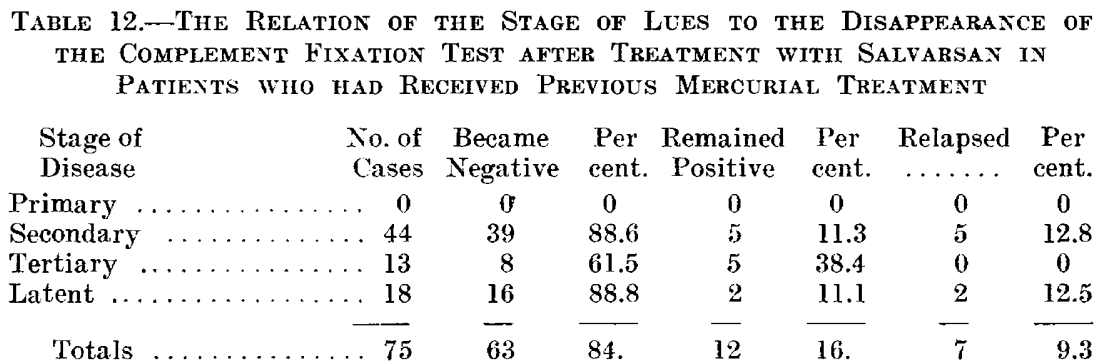

There were sixty-seven patients in the secondary stage of the disease who had not received mercurial treatment before salvarsan was administered. Of these 71.6 per cent. became negative and 16.6 per cent. relapsed. There were forty-four cases in the secondary stage which had received previous mercurial treatment, of which 88.6 per cent. became negative, while 12.8 per cent. relapsed. It is thus evident that better results were obtained in the secondary stage of the disease in the cases which had previously had mercurial treatment.

Eight patients in the tertiary stage who had not received previous mercurial treatment were tested; of the cases 62.5 per cent. became negative, while none relapsed. Thirteen patients in the same stage of the disease, which had received mercurial treatment, were tested, of which 61.5 per cent. became negative, none of which relapsed. Though the figures show a slight increase in the percentage of negative results in the untreated patients $I$ believe that this is only apparent and that if the same number of patients in both classes had been treated the results would have been in favor of those who had received previous mercurial treatment.

Considering the latent infections eight patients were tested who had received no previous mercurial treatment; of these 87.5 per cent. became negative and none relapsed, while of eighteen patients who had received previous mercurial treatment 88.8 per cent. became negative and 12.5 per cent. relapsed. The two patients who relapsed had previously had severe lesions which were quiescent at the time the patients were treated, while in the patients who had received no mercurial treatment the histories show that the infection was of mild character. I do not believe that any conclusions can be drawn from the fact that relapses occurred in the patients treated with mercury, while none occurred in the untreated patients. 
The time of disappearance of the reaction after treatment with salvarsan in various stages of the disease in patients given previous mercurial treatment and in those who had not received such treatment is shown in Tables 13 and 14 .

Table 13.-The Time of Disappearance of the Complement Fixation Test after Treatmest with Salvarsan in Patients who had Received no Previous Mercurial Treatment

\begin{tabular}{|c|c|c|c|c|c|c|c|c|c|}
\hline \multirow[b]{2}{*}{ Stage of Disease } & \multirow[b]{2}{*}{  } & \multicolumn{8}{|c|}{-Date of Disappearance of Test in Weeks- } \\
\hline & & $\begin{array}{l}\frac{y}{d} \\
\dot{0} \\
-\end{array}$ & $\frac{\pi}{\frac{\pi}{g}}$ & 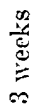 & 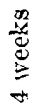 & 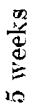 & 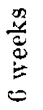 & 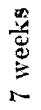 &  \\
\hline Primary & 22 & 2 & 12 & 3 & 3 & 1 & 1 & 0 & 0 \\
\hline Secondary & 48 & 6 & 11 & 13 & 6 & 4 & 6 & 1 & 1 \\
\hline Tertiary & 5 & 1 & 2 & 1 & 0 & 1 & 0 & $\mathbf{0}$ & 0 \\
\hline Latent. & 7 & 1 & 1 & 1 & 1 & 2 & 1 & 0 & 0 \\
\hline Totals & 82 & 10 & 20 & 18 & 10 & 8 & 8 & 1 & 1 \\
\hline
\end{tabular}

A comparison of these tables shows that there is little difference in the rate of disappearance of the reaction in either class of patients. This fact is of interest as it supports the theory that the time of disappearance depends on the rate of elimination of the substance or substances derived from the dead spirochetes or produced by the reaction of the tissues to them, the slight difference in favor of the previously treated patients being due to the destruction of a portion of the parasites, prior to the administration of salvarsan.

Table 14.-The Time of Disappearance of the Complement Fixation Test after Treatment with Salvarsan in Patients who had Received Previous Mercurial Treatment

\begin{tabular}{|c|c|c|c|c|c|c|c|c|}
\hline $\begin{array}{l}\text { Stage of } \\
\text { Disease }\end{array}$ & 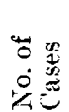 & $\begin{array}{l}\frac{x}{4} \\
\frac{1}{2} \\
-2\end{array}$ & 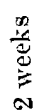 & 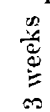 & 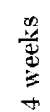 & 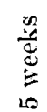 & 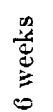 &  \\
\hline Primary & 0 & 0 & 0 & 0 & 0 & 0 & 0 & 0 \\
\hline Secondary & 39 & 4 & 10 & 10 & 8 & 5 & 2 & 0 \\
\hline Tertiary & 8 & 1 & 3 & 3 & 0 & 0 & 1 & 0 \\
\hline Latent & I6 & 0 & 5 & 3 & 4 & 2 & 2 & 0 \\
\hline Totals & 63 & 5 & 18 & 16 & 12 & 7 & 5 & 0 \\
\hline
\end{tabular}

The relative efficiency of salvarsan and mercury in causing a disappearance of the fixation reaction is strikingly illustrated in the cases of patients who had previously received mercurial treatment. Of fiftythree patients who were treated with mercury by the mouth for nine months or more before the administration of salvarsan and who gave a positive Wassermann reaction, all became negative within eight weeks after the administration of this drug. The intensity of the reaction in 
these cases is shown in Table 15, together with the time of previous mercurial treatment.

Table 15.-The Results of the Complement Fixation Test in Fifty-Three Patients who had Received Mercurial Treatmext Before the Administration of Salvarsan

$\begin{array}{lc}\text { Method of } & \begin{array}{c}\text { Time of } \\ \text { Treatment }\end{array} \\ \text { Treatment } \\ \text { Internal } & 9 \text { months } \\ \text { Internal } & 1 \text { year } \\ \text { Internal } & 2 \text { years } \\ \text { Internal } & 3 \text { years } \\ & \text { Totals }\end{array}$

No. of
Cases
17
19
11
$\frac{6}{53}$

\begin{tabular}{rrr}
\multicolumn{2}{c}{ Character } & of \\
++ & + & Reaction \\
+ & + & \pm \\
8 & 7 & 2 \\
11 & 6 & 2 \\
3 & 7 & 1 \\
2 & 3 & 1 \\
\hline 24 & -23 & -6
\end{tabular}

It will be observed from a consideration of Table 15 that nineteen of the patients had received mercury internally for one year, of whom eleven still gave a double-plus reaction; that eleven had received internal treatment for two years, of whom three still gave a double-plus reaction, and that six patients had received internal treatment for three years, of whom two still gave a double-plus reaction, while the remainder gave a plus or a well-marked plus-minus reaction. Comparing these results with those obtained after the administration of salvarsan, all of the cases becoming negative within eight weeks, and in a vast majority of instances after only one injection of the latter drug, the infinitely greater specific action of salvarsan is clearly demonstrated.

It is generally admitted that the most efficient method of administering mercury is by the hypodermic injection of suitable salts of the metal. Ten of the patients in whom the complement fixation test was still positive had been treated in this manner before the administration of salvarsan and the number of mercurial injections and the intensity of the reaction was as follows:

Two patients had received 7 injections and gave a double-plus reaction.

One patient had received 8 injections and gave a plus reaction.

One patient had received 9 injections and gave a double-plus reaction.

One patient had received 11 injections and gave a double-plus reaction.

One patient had received 15 injections and gave a plus reaction.

One patient had received 18 injections and gave a double-plus reaction.

One patient had received 20 injections and gave a plus reaction.

One patient had received 25 injections and gave a plus reaction.

One patient had received 30 injections and gave a plus reaction.

After one intramuscular injection of salvarsan the complement fixation test in all of these patients became negative and has remained so until the present time, most of them having been observed for from two to four months. While the previous mercurial treatment must have had some effect on the infections, perhaps rendering them more sensitive to the action of salvarsan, I think it must be admitted that the results amply demonstrate the superior specific action of the latter drug. 


\section{DISCUSSION OF RELAPSES}

It has been stated that of the 225 cases analyzed in this paper, twentyfour, or 14.6 per cent. have relapsed. In order to understand the exact significance of these results it is necessary to consider the cases somewhat in detail. ${ }^{10}$

First, as regards the relation of the stage of lues to relapses. In the primary stage three of the twenty-five cases which became negative, or 12 per cent., relapsed; in the secondary stage fifteen out of 100 cases, or 15 per cent.; in the tertiary stage, two of twelve cases, or 16.6 per cent.; and in the latent stage four of twenty-seven cases, or 14.8 per cent. It will thus be seen that the prognosis as regards relapses after treatment with salvarsan is best in the primary stage and most unfavorable in the tertiary, while it is better in the latent cases than in the secondary. Of course it is yet too early to conclude that no more relapses will occur in this series of cases, but the figures are correct, at least, as regards the occurrence of early relapses.

Second, the relation of the intensity of complement fixation to relapses. The complement fixation test gave a double plus reaction before treatment with salvarsan in sixteen of the twenty-four cases which relapsed; a plus reaction in six of the cases, and a plus-minus reaction in two of the cases. Therefore, the prognosis as regards relapse varies with the intensity of complement fixation, the best results being obtained in the cases giving a plus-minus reaction and the worst in those giving a double-plus reaction. This fact is of interest as it indicates that there is some relation between the intensity of complement fixation and the resistance of lues to treatment with salvarsan. That this is true is strikingly illustrated when one correlates the stage of the disease and the intensity of the reaction with the percentage of relapses. Thus, as is shown in Table 8 , the relapses occurring in the primary stage of lues were all in patients giving a double-plus reaction, no less than 30 per cent. of such patients relapsing, while no relapses occurred in patients giving a plus or a plus-minus reaction. The same is true in the tertiary cases, 50 per cent. of the patients giving a double-plus reaction relapsing, while no relapses occurred in those giving a plus or a plus-minus reaction.

In the secondary cases the largest percentage of relapses occurred in patients giving a double-plus reaction, but relapses also occurred in cases giving a plus and a plus-minus reaction, the percentage decreasing with the severity of the reaction. An apparent exception to the rule is noted in the latent cases, where 25 per cent. giving a plus reaction relapsed and only 14 per cent. giving a double-plus reaction, but there were only four patients tested who gave a plus reaction while there were fourteen tested giving a double-plus reaction, so that it is probable that had the

10. Since writing the above, the percentage of relapses has increased slightly. 
same number of patients in each class been tested the results would have been similar to those obtained in the other stages of the disease.

Third, the relation of the method of administration of salvarsan to the occurrence of relapses. The percentage of relapses varying greatly with the method of administration of salvarsan.

The neutral suspension of the drug was used in nine cases, of which seven became negative and five, or 71.4 per cent., relapsed. The alkaline intramuscular injection was used in 150 cases, of which 118 became negative and eight, or 6.7 per cent., relapsed. The intravenous method was used in thirty cases of which sixteen became negative and six, or $3 \% .5$ per cent., relapsed. The combined intramuscular and intravenous method was used in thirty-six cases, of which twenty-three became negative and five, or 21 per cent., relapsed. From these data it is evident that the intramuscular injection of the alkaline solution has given the best results as regards the occurrence of early relapses and the neutral suspension the poorest, while the combined intramuscular and intravenous has given better results than the intravenous method alone. It is also evident that the neutral suspension, as recommended by Wechselmann, should be discarded as a method of administering the drug.

Fourth, the relation of previous mercurial treatment to relapses. A slightly smaller percentage of relapses occurred in the secondary cases which had received previous mercurial treatment than in those which had not, but I do not believe that any conclusions can be drawn from the data relating to this phase of the subject, as in the vast majority of cases the amount of mercurial treatment was small and apparently had but little effect as regards the occurrence of relapse. In the latent cases which had received previous mercurial treatment 12.5 per cent. relapsed, while in those which had received no mercurial treatment relapses did not occur. A much smaller number of cases belonging to the latter class were tested. however, and therefore the results are untrustworthy and general conclusions cannot be drawn from them. (See Tables 11 and 12.)

THE TIME OF OCCURRENCE OF RELAPSES AFTER SALVARSAN

In considering this portion of our subject it should be remembered that I am only able to give the data concerning the relapses which have occurred in from one to six months after treatment and that the large majority of negative cases have only been observed for three months since the reaction became negative. It is more than probable that some of these cases will relapse later, but the results obtained indicate that the majority of relapses occur within eight weeks after the reaction becomes negative and that comparatively few occur after three months. Table 16 shows the time of occurrence of the relapses in the twenty-four cases under discussion, the time being given in weeks and computed from the date on which the complement fixation test became negative. 
Table 16.-Time of Relapse in Twenty-Four Patients Treated with SALVARSAN

$\begin{array}{cccccc}\begin{array}{c}\text { Time of Relapse } \\ \text { in Weeks }\end{array} & \begin{array}{c}\text { No. of } \\ \text { Cases }\end{array} & \begin{array}{c}\text { Time of Relapse } \\ \text { in Weeks }\end{array} & \begin{array}{c}\text { No. of } \\ \text { Cases }\end{array} & \begin{array}{c}\text { Time of Relapse } \\ \text { in Weeks }\end{array} & \begin{array}{c}\text { No. of } \\ \text { Cases }\end{array} \\ 4 \text { weeks } & 2 & 9 \text { weeks } & 1 & 16 \text { weeks } & 1 \\ 5 \text { weeks } & 4 & 10 \text { weeks } & 1 & 22 \text { weeks } & 1 \\ 6 \text { weeks } & 3 & 11 \text { weeks } & 2 & 23 \text { weeks } & 1 \\ 7 \text { weeks } & 4 & 12 \text { weeks } & 2 & \ldots \ldots \ldots & . \\ 8 \text { weeks } & 1 & 14 \text { weeks } & 1 & \ldots \ldots \ldots & - \\ \ldots \ldots \ldots & 14 & \ldots \ldots \ldots & \frac{1}{7} & \ldots \ldots \ldots & 3\end{array}$

It is evident from the table that more than half of the relapses occurred within eight weeks after the reaction became negative and that twenty-one of the twenty-four patients relapsed within fourteen weeks. I believe that these results indicate that, in the vast majority of instances, a relapse will occur within six months if it is going to, and that if a previously positive Wassermann test remains negative for as long as a year after the administration of salvarsan, provided clinical symptoms are absent, a relapse will not occur. I realize that this opinion is contrary to that held by many, i. e., that several years must elapse before one can be sure that this drug really cures lues, but I believe that unless the spirochetes are destroyed clinical symptoms will appear or the complement fixation test will become positive within a year, provided mercurial treatment is withheld.

I think that most authorities would consider a patient as cured who had taken a course of mercurial treatment and whose blood gave a negative Wassermann reaction a year after the cessation of such treatment, and I can see no reason why the same standard should not hold good in the treatment of this disease with salvarsan. Indeed, the mere fact that one or two injections of this drug has been followed by as good results as three years' treatment with mercury, as regards the complement fixation test, should render this standard more conclusive in the case of salvarsan than in the case of mercury. I am aware that clinical relapses sometimes occur with a negative Wassermann reaction, but I am very sure that a patient showing neither clinical symptoms nor a positive Wassermann reaction within a year after treatment with salvarsan may be considered as cured of syphilitic infection. Exceptions may occur but they will be the exceptions which will prove the rule.

\section{GENERAL CONCLUSIONS}

From the analyses of complement fixation tests after the administration of salvarsan which are given in this paper $I$ believe that the following conclusions may be safely drawn.

1. The best results, as regards the disappearance of the complement fixation test and the occurrences of relapses, are obtained in the treatment 
of patients in the primary stage of lues and the poorest in the treatment of those in the tertiary stage.

2. The complement fixation reaction disappears somewhat more rapidly after treatment with salvarsan in the tertiary stage than in either the primary or secondary stage of the disease.

3. The reaction in our experience has disappeared during the second, third and fourth weeks after treatment in the vast majority of the negative cases.

4. The prognosis, both as regards the disappearance of the reaction and the occurrence of relapses, is most favorable in patients giving a plus-minus reaction and least so in those giving a double-plus reaction.

5. As regards the method of administration of salvarsan the best results have been obtained, in our experience, from the intramuscular injection of the alkaline solution and the poorest from the use of the neutral suspension. In justice to the intravenous method, however, it should be stated that a smaller number of cases have been tested and it may be that this method will prove as efficient as the intramuscular.

6. The complement fixation reaction disappears more rapidly after the intravenous administration of salvarsan than after the intramuscular administration.

7. As regards the disappearance of the complement fixation reaction better results were obtained in patients who had previously received mercurial treatment than in those who had not, but the time of disappearance of the reaction was little affected.

8. The great superiority of salvarsan over mercury, as a specific remedy, was shown in the rapid and apparently permanent disappearance of the reaction, after one or two injections of the drug, in patients previously treated for one, two or three years with mercurials and in whom the reaction had remained positive.

9. The complement fixation test is of the very greatest value as a guide to treatment with salvarsan and it is the only method we possess of determining whether lues is actually cured by any therapeutic agent.

Finally, I believe that the data recorded in this paper eloquently sustain Ehrlich's modest claim, "11 "that the introduction of ' 606 ' makes a considerable advance in the therapy of syphilis, an advance which is not due to accident, but to the result of systematic experimental work."

11. Ehrlich, P.: Chemotherapy, Ed. 1, New York, 1911, p. 127. 